\title{
Essential and long-chain polyunsaturated fatty acid status and fatty acid composition of breast milk of lactating adolescents
}

\author{
Flávia Meneses, Alexandre G. Torres and Nádia M. F. Trugo* \\ Laboratório de Bioquímica Nutricional e de Alimentos, Departamento de Bioquímica, Instituto de Química, Universidade Federal \\ do Rio de Janeiro, Cidade Universitária, CT/ Bl. A, 21949-909, Rio de Janeiro, Brazil
}

(Received 18 September 2007 - Revised 2 January 2008 - Accepted 31 January 2008 - First published online 29 February 2008)

The aims of the present study were to evaluate essential fatty acids (EFA) and long-chain PUFA (LCPUFA) status in lactating adolescents and its association with breast milk composition. Healthy nursing adolescents from Rio de Janeiro, Brazil ( $n$ 30; $14-19$ years; 30-120 d postpartum), exclusively or predominantly breast-feeding, participated in this study. Breast milk and blood samples were collected after overnight fasting. Fatty acid composition of breast milk, erythrocyte membrane (EM) and plasma NEFA were determined by GC. Indices of fatty acid status (mean melting point (MMP); EFA status index; DHA status indices, 22:5n-6:22:4n-6 and 22:6n-3:22:5n-6 ratios) were calculated from EM fatty acid composition. Dietary intake of $n-3$ fatty acids was low when compared with current recommendations for lactating women. MMP was associated with indices of DHA status, some individual fatty acids in EM and years post-menarche and weeks postpartum, suggesting the use of erythrocyte MMP as a possible comprehensive biochemical marker of LCPUFA status in this physiological condition. The DHA status of lactating adolescents and their milk DHA concentrations were similar to the values of Brazilian lactating adults, but lower compared with the values of lactating adults from other countries. Therefore, these lactating adolescents were apparently not disadvantaged, as compared with the Brazilian adults, when EM and breast milk fatty acid composition were considered. In general, PUFA in milk from adolescents presented few associations with their concentrations in plasma NEFA and with maternal status. However, milk DHA was associated with maternal LCPUFA and DHA states.

Lactation in adolescence: Erythrocyte PUFA status: NEFA: Breast milk

Pregnancy during adolescence accounts for up to one-fifth of all births worldwide ${ }^{(1)}$ and the situation is similar in Brazil, where $21 \%$ of the babies born in the public health system are from adolescent mothers ${ }^{(2)}$. Adolescence is an intense anabolic period, characterized by linear growth, increase in body mass, development of internal organs and systems, skeletal and sexual maturation and changes in the amount and distribution of adipose tissue ${ }^{(3)}$. When pregnancy and subsequent lactation are superimposed upon adolescence, nutritional risks associated with each condition may be further enhanced. Nutritional surveys show that adolescents have dietary habits that differ from those of adults $^{(4)}$ and, in regard to fat intake, they present a relatively high intake of food sources of saturated fat and low intake of food sources of polyunsaturated $\mathrm{fat}^{(5,6)}$. Therefore, essential fatty acids (EFA; $18: 2 n-6$ and $18: 3 n-3)$ and $n-6$ and $n-3$ longchain PUFA (LCPUFA) status in adolescent mothers might be poorer than in adult mothers.

The habitual diet and maternal fatty acid status influence the fatty acid composition of breast milk ${ }^{(7,8)}$, which is an important source of EFA and LCPUFA to infants. LCPUFA, especially arachidonic acid (AA; 20:4n-6) and DHA (22:6n-3), are indispensable functional and structural components of all cellular membranes and are required for neural, visual and vascular development in infants ${ }^{(9)}$. Studies with adult women have shown that the intake of EFA and LCPUFA from the diet or from supplements affects maternal status during gestation ${ }^{(10-12)}$ and lactation $^{(13,14)}$ and milk composition ${ }^{(13-17)}$.

The maternal circulating fatty acids are the major direct sources of LCPUFA present in human milk $^{(18,19)}$. They are available to the mammary gland from VLDL TAG, which are synthesized in the liver, chylomicron TAG, from the maternal diet, and plasma NEFA, from maternal adipose tissue. Therefore, maternal circulating fatty acids affect EFA transfer to breast milk. In a previous study with Brazilian lactating adult women, both the $n-6$ and $n-3$ fatty acids in human milk were associated with NEFA composition ${ }^{(20)}$.

The fatty acid composition of the erythrocyte membrane (EM) has been used as a biochemical and functional index of EFA and LCPUFA maternal status ${ }^{(12,21-24)}$ and as a biochemical marker of intake of fatty acids not synthesized endogenously ${ }^{(10,13,25-27)}$. In addition, the fatty acid composition of EM showed associations with breast milk $n$ - 3 PUFA in adult lactating women ${ }^{(20)}$. Several indices derived from fatty acid composition in structural phospholipids, such as those of the EM,

Abbreviations: AA, arachidonic acid; EFA, essential fatty acids; EFASTI, EFA status index; EM, erythrocyte membrane; FAME, fatty acid methyl esters; IGF-1, insulin-like growth factor 1; LCPUFA, long-chain PUFA; MMP, mean melting point.

* Corresponding author: Nádia M. F. Trugo, fax +55 212562 7266, email trugo@iq.ufrj.br 
have been proposed and used as proxies for EFA and LCPUFA status in different studies ${ }^{(24,28-30)}$. Some of these are the mean melting point $\left(\mathrm{MMP}=\sum\left(\mathrm{mol} \% \times\right.\right.$ melting point $\left({ }^{\circ} \mathrm{C}\right)$ of individual fatty acids) $)^{(28)}$, the DHA indices $(22: 6 n-3: 22: 5 n-6$ and $22: 5 n-6: 22: 4 n-6$ ratios) $)^{(24,29)}$ and EFA status index $\left(\text { EFASTI }=\left(\sum n-3+\sum n-6\right) /\left(\sum n-7+\sum n-9\right)\right)^{(24)}$, which are useful for comparison within and between different studies. These indices provide complementary information and when used together are likely to give better estimates of EFA and LCPUFA maternal status, although cut-off values to define sufficiency or deficiency based on physiological or clinical outcomes have not yet been clearly established.

The impact of lactation on the adolescent status of EFA and LCPUFA has not been reported and the association between milk fatty acid composition and plasma NEFA and EM composition has not been evaluated in lactating adolescents. The aims of the present study were to evaluate EFA and LCPUFA status in lactating adolescents and its association with breast milk composition.

\section{Methods and materials}

\section{Volunteers and data collection}

Adolescent nursing mothers, apparently healthy, attending four public day-care clinics of the Municipal Health Secretary in Rio de Janeiro, Brazil, were recruited during the appointment with their babies' paediatricians for this cross-sectional study. The study protocol was approved by the Ethics Committee of the Municipal Health Secretary of Rio de Janeiro and its conduction was in accordance with the Declaration of Helsinki. The four clinics chosen were reference clinics for adolescent mothers, predominantly of low socio-economic status, and were located in different regions of the city.

First, a screening for potential participants of the study was done for a period of 6 months through interviews during regular attendance to the clinics and through their medical records. The study eligibility criteria were: (1) adolescent mothers (14-19 years) of a healthy full-term singleton infant, exclusively or predominantly breast-fed (breast milk plus sparse use of water, water-based infusions, such as teas and herbs, and water-diluted fruit juices, without substituting a feeding from the breast ${ }^{(31)}$; (2) years post-menarche ranging from 2 to 6 ; 3) absence of chronic diseases or process of acute illness; (4) 30-120 d postpartum at the time of milk collection; (5) no intake of dietary supplements; (6) amenorrhoea.

Thirty adolescents, who met the eligibility criteria, who were willing to participate and had the consent of their parents/relatives or legal tutors, were enrolled in the present study. All participants and/or one of their parents/relatives or legal tutors signed an informed consent form prior to enrolment.

The enrolled mothers were asked to return on appointed days within 1 or 2 weeks of the first contact for milk and blood sampling and for dietary assessment. On the appointed day, maternal weight and height were measured and the BMI $\left(\mathrm{kg} / \mathrm{m}^{2}\right)$ was calculated. Dietary intake was estimated through three $24 \mathrm{~h}$ dietary recall questionnaires, starting on the appointed day and followed by two more interviews 1 week apart. To facilitate maternal report of food portion sizes, a photographic index of foods was used. Energy and fat intakes were quantified by The Food Processor Nutrition Analysis software, version 7.20 (ESHA Research, Salem, OR, USA), with the database adapted for use of the most common fat sources in the Brazilian diet ${ }^{(32)}$. Additionally, data on frequency of intake of fish, vegetable oils, margarine and butter were obtained in detail through a specific FFQ.

General data on maternal characteristics (chronological age, age at menarche, duration of gestation, use of supplements, weeks postpartum, breast feeding practices, socio-economic status and education level) and on infant's weight and length at birth were obtained through standardized questionnaires and medical records on the day of the first contact.

\section{Collection and analyses of blood and breast milk samples}

Breast milk and venous blood samples were collected once in the morning (08.00 to 10.00 hours) from all volunteers, after fasting for approximately $11 \mathrm{~h}$, which was within the time required for sampling blood to analyse fasting NEFA, insulin, glucose and insulin-like growth factor 1 (IGF-1).

Milk was collected by complete expression with a manual syringe-style breast pump from the breast that was not suckled in the previous feeding, which occurred 90-180 min earlier (135 (SD 38) min). Milk aliquots were taken for immediate determination of total fat content by the crematocrit method $^{(33)}$. Milk samples were stored in glass tubes at $-20^{\circ} \mathrm{C}$ under $\mathrm{N}_{2}$, for up to 1 month, for analyses of total milk protein ${ }^{(34)}$, lactose ${ }^{(35)}$ and fatty acids.

Venous blood samples $(4 \mathrm{ml})$ were collected immediately before milk collection by venipuncture into tubes, containing or not containing K-EDTA as anticoagulant, which were kept on ice. Aliquots of whole blood were separated for immediate determination of haematocrit, by centrifugation in capillary tubes (Hemospin centrifuge; Incibrás, São Paulo, Brazil), and of haemoglobin concentration, by the cyanomethemoglobin reaction (BioClin-Quibasa kit, Sao Paulo, Brazil). Plasma or serum was immediately separated from the cell fraction by centrifugation at $4^{\circ} \mathrm{C}$, divided in aliquots and stored for up to 1 month at $-20^{\circ} \mathrm{C}$ under $\mathrm{N}_{2}$ for later analyses. Plasma was used for analysis of NEFA, and serum aliquots were used for determinations of insulin (solid-phase RIA; Coat-a-Count Insulin, Diagnostic Products Corporation, Los Angeles, CA, USA), glucose (glucose oxidase method; BioClin-Quibasa kit) and IGF-1 (IRMA, Diagnostic Systems Laboratories-DSL, TX, USA). The packed erythrocytes were washed three times with isotonic $\mathrm{NaCl}(9 \mathrm{~g} / \mathrm{l})$ after removal of the buffy coat. The washed erythrocytes were suspended in an equal volume of isotonic $\mathrm{NaCl}$ and stored at $-20^{\circ} \mathrm{C}$ with sodium dithionite at a final concentration of $10 \mathrm{~g} / \mathrm{l}$ in the erythrocyte suspension to avoid oxidation of unsaturated fatty acids ${ }^{(36)}$.

\section{Analyses of fatty acids in milk, plasma and erythrocyte samples}

For the analyses of milk fatty acids, samples were defrosted in a water bath $\left(38^{\circ} \mathrm{C}\right)$ and homogenized by inversion and by agitation in an ultra-sonic bath to disperse the coalesced fat. Total lipids were extracted from $1.0 \mathrm{ml}$ milk aliquots, in duplicates, by the method of Bligh \& Dyer ${ }^{(37)}$ as described by Jensen et al. $^{(38)}$. The chloroform extracts, containing butylhydroxytoluene (1 g/l; Sigma Chemical Co., St Louis, MO, 
USA), were dried under $\mathrm{N}_{2}$ and the residue was suspended in $10.0 \mathrm{ml}$ chloroform-methanol $(10: 1, \mathrm{v} / \mathrm{v})$ and stored at $-20^{\circ} \mathrm{C}$ in glass vials with polytetrafluoroethylene lined screw caps with a $\mathrm{N}_{2}$ atmosphere. Milk fatty acids were methylated by the use of the transesterification method of Kramer et al. ${ }^{(39)}$ and extracted as described by Torres et al. ${ }^{(20)}$. The fatty acid methyl esters (FAME) were analysed by GC as described by Torres et al. ${ }^{(40)}$.

Erythrocyte fatty acids were analysed as previously described $^{(20)}$.

NEFA were isolated from plasma, after addition of the internal standard (17:0), with fumed silicon dioxide according to Polette et $a l{ }^{(41)}$. After transesterification, the resulting FAME were analysed by GC using splitless injection as described elsewhere ${ }^{(20,42)}$.

FAME from milk, erythrocyte and plasma samples were analysed in a Shimadzu GC-14B (Kyoto, Japan) gas chromatograph, using an Omegawax-320 column (Supelco Co., Bellefonte, PA, USA). FAME were identified as described by Torres et al. ${ }^{(20,40)}$.

All the materials used for sample storage and analyses were thoroughly rinsed with alcoholic potassium hydroxide $(25 \mathrm{~g} / \mathrm{l})$ and soaked in nitric acid $(130 \mathrm{~g} / \mathrm{l})$ for at least $2 \mathrm{~h}$. All organic solvents used were of chromatographic grade (Tedia, São Paulo, Brazil) and were periodically tested for the presence of peroxides (Merkoquant ${ }^{\circledR}$ test stripes; Merck, Darmstadt, Germany). Samples were analysed as duplicates, and interand intra-assay $\mathrm{CV}$ for the gas-chromatographic analyses were as previously reported ${ }^{(40,42)}$.

To evaluate the EFA and DHA status of the volunteers, the following indices ${ }^{(24)}$ were used as proxies for status and were calculated from the composition of erythrocyte fatty acids: EFASTI was obtained by dividing the sum of the essential $n-3$ and $n-6$ fatty acids by the sum of the non-essential $n-7$ and $n-9$ fatty acids; DHA indices were calculated as the $22: 6 n-3: 22: 5 n-6$ and $22: 5 n-6: 22: 4 n-6$ ratios. Increased $22: 6 n-3: 22: 5 n-6$ indicates a balance between metabolic equivalent members of $n-3$ and $n-6$ LCPUFA, which favours $\mathrm{DHA}^{(29)}$. Therefore, the higher this index, the higher the functional DHA status ${ }^{(24)}$. On the other hand, increased $22: 5 n$ 6:22: $4 n-6$ indicates a balance favourable to $n-6$ LCPUFA in relation to $\mathrm{DHA}^{(24,29)}$. Therefore, the higher this index, the lower the functional DHA status ${ }^{(24)}$.

The MMP, which is an index of 'fluidity' and possibly of PUFA deficiency, was determined on the basis of the fatty acid composition of the $\mathrm{EM}^{(28)}$. MMP was calculated by summing the products of mole fraction times melting point $\left({ }^{\circ} \mathrm{C}\right)^{(43)}$ for each fatty acid in the mixture.

\section{Statistical analysis}

Data were analysed with Statgraphics v. 7 (Statistical Graphics Corporation, Manugistics, Inc., Cambridge, MA, USA). Variables with non-normal distribution were normalized with log transformation before analysis. Pearson correlation analysis was used to investigate associations among continuous variables (milk fatty acids, plasma NEFA, erythrocyte fatty acids, EFASTI, DHA indices, MMP, BMI, age, years post-menarche, weeks postpartum, insulin, glucose, insulin:glucose ratio, IGF-1).

Multiple regression analysis was performed between: (a) selected breast milk PUFA (dependent variables) and fatty acids in NEFA and in EM (independent variables); (b) MMP (dependent variable) and EM fatty acids (independent variables). Fatty acids were included as independent variables based on biological relevance and/or on the Pearson correlation analysis results. Independent variables that presented $P>0.05$ for their coefficients in the model were maintained when their exclusion resulted in worse values for adjusted $R^{2}$ and mean absolute error of estimated value. The final models were further evaluated by the aid of their respective normal probability plots. Two-sided $P$ values $<0.05$ were considered as statistically significant.

\section{Results}

Table 1 presents the general characteristics, breast milk macronutrients and dietary fat intake of the adolescents participating in the present study. The average BMI was within the range for eutrophic populations ${ }^{(31)}$. Total lipid intake contributed to approximately $27 \%$ of the total energy intake of the volunteers and was within the acceptable macronutrient distribution ranges ${ }^{(44)}$, whereas $n-3, n-6$ and total PUFA mean intakes were lower than the acceptable macronutrient distribution ranges ${ }^{(44)}$. Only $10 \%$ of the volunteers reported regular intake of fish and fish products, showing a low intake of a major source of $n-3$ LCPUFA. All volunteers reported a daily intake of foods prepared with soyabean oil, which is the main source of EFA, especially $18: 2 n-6$. Margarine and butter, sources of saturated and monounsaturated fat, were regularly consumed by $90 \%$ of the mothers.

Duration of gestation was 38.8 (SD 1.6) weeks and infants' birth weight and birth length were, respectively, $3 \cdot 1$ (SD 0.59) $\mathrm{kg}$ and $49.6(\mathrm{SD} 3 \cdot 3) \mathrm{cm}$.

Table 1. General characteristics, breast milk composition and dietary fat intake of the lactating adolescents $(n 30)^{*}$

(Mean values and standard deviations)

\begin{tabular}{|c|c|c|}
\hline & Mean & SD \\
\hline \multicolumn{3}{|l|}{ Characteristics } \\
\hline Age (years) & $16 \cdot 6$ & 1.4 \\
\hline Years post-menarche & $5 \cdot 0$ & $2 \cdot 2$ \\
\hline BMI $\left(\mathrm{kg} / \mathrm{m}^{2}\right)$ & $24 \cdot 1$ & 3.5 \\
\hline Haematocrit (\%) & $38 \cdot 9$ & $3 \cdot 3$ \\
\hline $\mathrm{Hb}(\mathrm{g} / \mathrm{l})$ & $12 \cdot 1$ & 1.6 \\
\hline Serum glucose $(\mathrm{mmol} / \mathrm{l})$ & $2 \cdot 72$ & 0.9 \\
\hline Serum insulin $(\mathrm{pmol} / \mathrm{l})$ & $32 \cdot 2$ & $16 \cdot 5$ \\
\hline Serum IGF-1 $(\mu \mathrm{g} / \mathrm{l})$ & 272 & 95 \\
\hline \multicolumn{3}{|l|}{ Breast milk composition } \\
\hline Protein $(g / l)$ & $11 \cdot 7$ & $2 \cdot 4$ \\
\hline Lactose (g/l) & $74 \cdot 3$ & $5 \cdot 7$ \\
\hline Fat $(g / l)$ & $32 \cdot 8$ & 11.4 \\
\hline \multicolumn{3}{|l|}{ Dietary fat intake } \\
\hline Total fat (en\%) & $27 \cdot 2$ & $5 \cdot 8$ \\
\hline Saturated (en\%) & $10 \cdot 2$ & $2 \cdot 3$ \\
\hline Monounsaturated (en\%) & $9 \cdot 1$ & 1.5 \\
\hline Polyunsaturated (en\%) & $4 \cdot 3$ & $2 \cdot 8$ \\
\hline$n-3(e n \%)$ & 0.4 & 0.1 \\
\hline$n-6(e n \%)$ & 3.4 & $1 \cdot 6$ \\
\hline$n-6: n-3$ & $7 \cdot 4$ & $3 \cdot 2$ \\
\hline$P: S$ & 0.4 & 0.2 \\
\hline
\end{tabular}

IGF-1, insulin-like growth factor 1 ; en\%, nutrient intake relative to energy intake (\%); P:S, polyunsaturated:saturated fat ratio.

*For details of subjects and procedures, see Methods and materials. 
Table 2 presents the fatty acid percentage composition ( $\mathrm{g} / 100 \mathrm{~g}$ total fatty acids) of the breast milk samples. Fatty acids with 10 to 14 carbons contributed to approximately $30 \%$ of the total milk fatty acids. Total SFA, MUFA, PUFA and LCPUFA ( $\geq 20$ carbons) comprised, respectively, 50.7 (SD 7.8) \%, 28.9 (SD 4.6) \%, 19.5 (SD 5.4) \% and 1.17 (SD 0.30 ) $\%$ of the total fatty acids. PUFA of the $n-6$ and $n-3$ series represented, respectively, 18.4 (SD 5.3) $\%$ and 1.7 (SD 0.5) $\%$, and the ratio $n-3: n-6$ was 0.089 (SD 0.010) $\%$. Three conjugated linoleic acid isomers were identified in the samples, amounting to about $0.3 \%$.

EM and plasma NEFA compositions ( $\mathrm{g} / 100 \mathrm{~g}$ total fatty acids) of the lactating women are presented in Table 3 . Nineteen fatty acids were identified in EM (Table 3); 16:0 and 18:0 were the major fatty acids. Total PUFA and LCPUFA comprised, respectively, $35 \%$ and $26 \%$ of the EM fatty acids and

Table 2. Fatty acid contents ( $\mathrm{g} / 100 \mathrm{~g}$ total fatty acids) in milk from lactating adolescents $(n 30) \dagger$

(Mean values and standard deviations)

\begin{tabular}{|c|c|c|}
\hline Fatty acid & Mean & SD \\
\hline \multicolumn{3}{|l|}{ Saturated } \\
\hline $8: 0$ & 0.21 & 0.08 \\
\hline $10: 0$ & $1 \cdot 82$ & 0.42 \\
\hline $12: 0$ & $8 \cdot 22$ & $2 \cdot 42$ \\
\hline $13: 0$ & $12 \cdot 1$ & $5 \cdot 20$ \\
\hline $14: 0$ & $7 \cdot 70$ & 2.74 \\
\hline $15: 0$ & 0.19 & 0.10 \\
\hline $16: 0$ & $15 \cdot 9$ & 2.06 \\
\hline $18: 0$ & $5 \cdot 32$ & 1.73 \\
\hline $19: 0$ & 0.23 & 0.12 \\
\hline $20: 0$ & 0.15 & 0.06 \\
\hline $21: 0$ & 0.03 & 0.01 \\
\hline $22: 0$ & 0.09 & 0.09 \\
\hline $24: 0$ & 0.11 & 0.09 \\
\hline \multicolumn{3}{|c|}{ Monounsaturated } \\
\hline $14: 1 n-7$ & 0.11 & 0.08 \\
\hline $14: 1 n-5$ & 0.05 & 0.05 \\
\hline $16: 1 n-9$ & 0.21 & 0.11 \\
\hline $16: 1 n-7$ & 1.61 & 0.66 \\
\hline $17: 1 n-9$ & 0.22 & 0.15 \\
\hline $18: 1^{*}$ & 24.6 & $5 \cdot 00$ \\
\hline $19: 1 n-9$ & 0.13 & 0.06 \\
\hline $20: 1 n-9$ & 0.27 & 0.08 \\
\hline $22: 1 n-9$ & 0.07 & 0.05 \\
\hline \multicolumn{3}{|l|}{ CLA } \\
\hline $18: 2-9 c, 11 t$ & 0.08 & 0.04 \\
\hline $18: 2-10 t, 12 c$ & 0.04 & 0.01 \\
\hline $18: 2-\mathrm{t}, \mathrm{t}$ & 0.18 & 0.18 \\
\hline \multicolumn{3}{|l|}{ Polyunsaturated } \\
\hline $18: 2 n-6$ & $17 \cdot 3$ & 4.78 \\
\hline $18: 3 n-6$ & 0.13 & 0.09 \\
\hline $20: 2 n-6$ & 0.37 & 0.10 \\
\hline $20: 3 n-6$ & 0.31 & 0.13 \\
\hline $20: 4 n-6$ & 0.40 & 0.15 \\
\hline $18: 3 n-3$ & 1.08 & 0.54 \\
\hline $18: 4 n-3$ & 0.32 & 0.14 \\
\hline $20: 3 n-3$ & 0.06 & 0.05 \\
\hline $20: 4 n-3$ & 0.09 & 0.08 \\
\hline $20: 5 n-3$ & 0.05 & 0.01 \\
\hline $22: 5 n-3$ & 0.21 & 0.13 \\
\hline $22: 6 n-3$ & 0.20 & 0.10 \\
\hline
\end{tabular}

CLA, conjugated linoleic acid.

*Includes the 18:1n-9, 18:1n-7 and 18:1n-5 isomers, which were considered together because separation was dependent on concentration in the samples. †For details of subjects and procedures, see Methods and Materials.
Table 3. Fatty acid contents ( $g / 100 \mathrm{~g}$ total fatty acids) of erythrocyte membrane (EM) and plasma NEFA in Brazilian lactating adolescents $(n 30)^{*}$

(Mean values and standard deviations)

\begin{tabular}{|c|c|c|c|c|}
\hline \multirow[b]{2}{*}{ Fatty acid } & \multicolumn{2}{|c|}{ EM } & \multicolumn{2}{|c|}{ NEFA } \\
\hline & Mean & SD & Mean & SD \\
\hline \multicolumn{5}{|l|}{ Saturated } \\
\hline $14: 0$ & 0.32 & 0.08 & 1.99 & 1.41 \\
\hline $16: 0$ & $22 \cdot 1$ & $3 \cdot 12$ & $29 \cdot 3$ & 3.66 \\
\hline $18: 0$ & $16 \cdot 5$ & $2 \cdot 18$ & 11.9 & 2.55 \\
\hline $20: 0$ & 0.45 & 0.28 & - & - \\
\hline $22: 0$ & 2.48 & 1.44 & - & - \\
\hline $24: 0$ & $5 \cdot 15$ & $1 \cdot 26$ & - & - \\
\hline \multicolumn{5}{|c|}{ Monounsaturated } \\
\hline $16: 1 n-7$ & 0.45 & 0.16 & $2 \cdot 88$ & 1.02 \\
\hline $18: 1 n-9$ & 8.93 & $1 \cdot 34$ & $22 \cdot 9$ & 4.40 \\
\hline $18: 1 n-7$ & $2 \cdot 14$ & 0.42 & 2.57 & 0.40 \\
\hline $20: 1 n-9$ & 0.38 & 0.28 & - & - \\
\hline $24: 1 n-9$ & 3.83 & $2 \cdot 10$ & - & - \\
\hline \multicolumn{5}{|c|}{ Polyunsaturated } \\
\hline $18: 2 n-6$ & $9 \cdot 73$ & $1 \cdot 82$ & $27 \cdot 1$ & 5.54 \\
\hline $18: 3 n-6$ & - & - & 1.52 & 0.65 \\
\hline $20: 3 n-6$ & $1 \cdot 26$ & 0.44 & 0.76 & 0.26 \\
\hline $20: 4 n-6$ & $12 \cdot 1$ & $1 \cdot 64$ & 2.64 & $1 \cdot 23$ \\
\hline $22: 4 n-6$ & 3.40 & 1.73 & - & - \\
\hline $22: 5 n-6$ & 0.91 & 0.38 & - & - \\
\hline $18: 3 n-3$ & - & - & 1.43 & 0.71 \\
\hline $20: 5 n-3$ & 0.99 & $1 \cdot 31$ & - & - \\
\hline $22: 5 n-3$ & $2 \cdot 38$ & 1.54 & - & - \\
\hline $22: 6 n-3$ & 4.50 & $1 \cdot 88$ & - & - \\
\hline
\end{tabular}

${ }^{*}$ For details of subjects and procedures, see Methods and materials.

those of the $n-6$ series, mainly AA and $18: 2 n-6$, were the most abundant PUFA. DHA was the major $n$-3 PUFA. PUFA of the $n-6$ and $n-3$ series were 27.7 (SD 2.6) $\%$ and 8.6 (SD 2.3) $\%$, respectively, and the $n-3: n-6$ ratio was $0 \cdot 32$ (SD $0 \cdot 13) \%$ in EM. Eleven fatty acids were identified in plasma NEFA. The major fatty acids in NEFA were $18: 0,18: 2 n-6$ and $18: 1 n-9$. PUFA of the $n-3$ series, except $18: 3 n-3$, and those with twenty-two carbons of the $n-6$ series were not detected in plasma NEFA. Conjugated linoleic acid was not detected in EM or NEFA.

The concentrations of the individual NEFA in $\mu \mathrm{mol} / \mathrm{l}$ plasma were also calculated (results not shown) and total NEFA was 753 (SD 360) $\mu \mathrm{mol} / \mathrm{l}$. There was no correlation between total plasma NEFA and IGF-1, fasting insulin, glucose or insulin: glucose ratio, either between total plasma NEFA and years post-menarche, weeks postpartum or BMI (Pearson's correlation analysis)

The results for the evaluation of PUFA status of the lactating adolescents, using indices based on the EM fatty acid composition, were: EFASTI 2.24 (SD 0.21); $22: 5 n$ $6: 22: 4 n-6$ ratio $0 \cdot 27$ (SD $0 \cdot 10) ; 22: 6 n-3: 22: 5 n-6$ ratio $5 \cdot 88$ (SD 4.03); MMP 24.8 (SD 3.0) ${ }^{\circ} \mathrm{C}$. These results are consistent with their dietary pattern of low intake of LCPUFA food sources, especially for the $n-3$ series.

MMP presented several correlations (Pearson analysis) with indices of PUFA status and with individual fatty acids. As expected, MMP was negatively associated $(P<0.05)$ with several individual LCPUFA (results not shown). MMP was also negatively associated with $n-3: n-6$ ratio $(r-0.58, P=0.029)$, EFASTI $(r-0.62, P=0.029)$ 
and $22: 6 n-3: 22: 5 n-6(r-0.66, P=0.014)$ and positively associated with $22: 5 n-6: 22: 4 n-6(r 0.59, P=0 \cdot 017)$. These correlations were used as the basis for choosing the independent variables that were entered in the models of MMP by multiple regression analysis.

The best resulting models for erythrocyte MMP obtained from multiple regression analysis are shown in Table 4. The best models obtained with individual fatty acids and years post-menarche (adjusted $R^{2} 0.61$ ) or weeks postpartum (adjusted $R^{2} 0.84$ ) as independent variables included $18: 0,20: 4 n-6,22: 4 n-6$ and $22: 6 n-3$ or $22: 4 n-6$ and $22: 6 n$ 3 , respectively. The best model (adjusted $R^{2} 0.94$ ) obtained with fatty acid status indices as independent variables included only SFA, PUFA and $22: 6 n-3: 22: 5 n-6$ ratio.

Similarly, multiple regression analysis was employed for modelling of milk EFA and LCPUFA, using selected NEFA and EM fatty acids or PUFA status indices as independent variables, based on significant associations found by Pearson correlation analysis (results not shown) and/or biological significance of the fatty acids. The variation of milk DHA was the only one that could be explained by maternal fatty acids through multiple regression analyses. The regression models for milk DHA are presented in Table 5. The best model obtained with individual fatty acids as independent variables (adjusted $R^{2} 0.72$ ) included only the two EFA in NEFA, linoleic and linolenic acids, one saturated fatty acid and one LCPUFA in the EM. In the case of fatty acid status indices, the best model (adjusted $R^{2}$ 0.98) included MMP, 22:5n-6:22:4n-6 and $22: 6 n-3: 22: 5 n-6$ ratios.

Associations of individual fatty acids in milk, plasma NEFA and EM and of $22: 5 n-6: 22: 4 n-6,22: 6 n-3: 22: 5 n-6$, EFASTI and MMP with age, years post-menarche, weeks postpartum, BMI, IGF-1, fasting insulin and glucose, and insulin:glucose ratio were assessed by Pearson correlation analysis. Significant correlations were found between weeks postpartum and MMP $(r-0 \cdot 55, P=0.027)$, EFASTI $(r 0.55$, $P=0.049)$, EM SFA $(r-0.66, P=0.004)$ and EM polyunsaturated:saturated fat ratio $(r 0.61, P=0.015)$; between years post-menarche and NEFA $n-3(r 0.51, P=0.030)$ and NEFA $18: 2 n-6(r-0.52, P=0.024)$; and between serum insulin:glucose ratio and EM $18: 2 n-6(r 0 \cdot 70, P=0 \cdot 002)$.

\section{Discussion}

There is a remarkable lack of studies on fatty acid composition of breast milk, EFA and LCPUFA status and their associations, in lactating adolescents. The present study carried out in Brazilian lactating adolescents is the first one to report these data.

The metabolic milieu during lactation favours fatty acid mobilization from adipose tissue and transfer to the mammary gland ${ }^{(45)}$. Accordingly, there is an increase in fasting plasma total NEFA of lactating adult women compared with non-lactating ones ${ }^{(46,47)}$. Fasting plasma total NEFA concentration in the lactating adolescents of the present study was similar to that of lactating adult women $\left(760 \mu \mathrm{mol} / \mathrm{l}^{(46)} ; 630 \mu \mathrm{mol} / \mathrm{l}^{(48)}\right)$.

Fasting serum insulin level and insulin:glucose ratio are reduced in lactating adult women ${ }^{(46,48)}$. This decrease was also observed in the lactating adolescents of the present study, whose fasting serum insulin level and insulin:glucose ratio were, respectively, three-fold lower and two-fold lower than those of non-pregnant, non-lactating adolescents ${ }^{(49)}$, but similar to those of adult lactating women ${ }^{(46,48)}$. As was the case for insulin concentration, IGF-1 concentration was similar to that of adult lactating women $(230 \mu \mathrm{g} / 1)^{(46)}$. Fasting serum insulin and IGF-1 concentrations in the lactating adolescents were not associated with fasting total NEFA or with fatty acid composition of NEFA, EM and milk.

Dietary fat intake of the lactating adolescents in the present study showed that $n-3, n-6$ and total PUFA mean intakes, expressed as percentage of total energy, were lower than the acceptable macronutrient distribution ranges ${ }^{(44)}$ and the intakes reported for Brazilian lactating women of similar socio-economic level $^{(20)}$, resulting in lower polyunsaturated:saturated fat ratio and higher $n-6: n-3$ ratios in the diet of lactating adolescents as compared with the lactating adult women. The PUFA intake pattern in the present study is consistent with recent studies in pregnant ${ }^{(6)}$ and in non-pregnant, non-lactating adolescents $^{(5)}$ in Brazil, which showed a relatively high intake of food sources of saturated fat and low intake of unsaturated fatty acids, especially a very low intake of fish, based on the intake frequency of food sources of lipids. Based on current scientific evidence, it has been suggested ${ }^{(50)}$ that pregnant and lactating women should aim for an average dietary intake of $200 \mathrm{mg}$

Table 4. Multiple regression analysis for modelling of erythrocyte membrane (EM) mean melting point (MMP)*

\begin{tabular}{llccc}
\hline $\begin{array}{l}\text { Erythrocyte membrane } \\
\text { (dependent variable) }\end{array}$ & $\begin{array}{c}\text { EM individual fatty acids, status indices and } \\
\text { maternal characteristics (independent variables) }\end{array}$ & Coefficient & Coefficient SE & $\begin{array}{c}\text { ANOVA for } \\
\text { Adjusted } R^{2}\end{array}$ \\
\hline the model $(P)$
\end{tabular}

*For details of subjects and procedures, see Methods and materials. 
Table 5. Multiple regression analysis for modelling of breast milk $D H A^{*}$

\begin{tabular}{|c|c|c|c|c|c|c|}
\hline $\begin{array}{l}\text { Breast milk } \\
\text { (dependent variable) }\end{array}$ & $\begin{array}{l}\text { Blood individual fatty acids or } \\
\text { status indices (independent variables) }\end{array}$ & Coefficient & Coefficient SE & $P$ & Adjusted $R^{2}$ & $\begin{array}{l}\text { ANOVA for } \\
\text { the model }(P)\end{array}$ \\
\hline $22: 6 n-3$ & Constant & 0.41 & 0.11 & 0.0018 & \multirow{5}{*}{0.72} & \multirow{5}{*}{0.0002} \\
\hline \multirow[t]{4}{*}{$(n 19)$} & NEFA $18: 2 n-6$ & -0.0071 & 0.0037 & 0.0742 & & \\
\hline & NEFA $18: 3 n-3$ & 0.026 & 0.014 & 0.0805 & & \\
\hline & EM 22:0 & -0.045 & 0.0098 & 0.0004 & & \\
\hline & EM $22: 4 n-6$ & 0.019 & 0.01 & 0.0779 & & \\
\hline $22: 6 n-3$ & EM MMP & 0.0053 & 0.002 & 0.0239 & \multirow{3}{*}{0.98} & \multirow{3}{*}{0} \\
\hline \multirow{2}{*}{$(n 13)$} & EM $22: 5 n-6: 22: 4 n-6$ & -0.21 & $0 \cdot 11$ & 0.0846 & & \\
\hline & EM $22: 6 n-3: 22: 5 n-6$ & 0.022 & 0.0056 & 0.0033 & & \\
\hline
\end{tabular}

EM, erythrocyte membrane; MMP, mean melting point.

${ }^{*}$ For details of subjects and procedures, see Methods and materials.

DHA/d and that women of childbearing age should consume one or two portions of oily fish per week to attain satisfactory pregnancy outcomes and desirable infant growth and development. According to these recommendations, DHA intake of the lactating adolescents in the present study is likely to be inadequate.

The EFA and LCPUFA status of lactating adolescents, as indicated by erythrocyte EFASTI and DHA indices (22:5n-6:22:4n-6 and $22: 6 n-3: 22: 5 n-6$ ratios), was not different from that of Brazilian adult women during lactation (2.3 (SD 0.27), 0.24 (SD 0.06), 6.5 (SD 1.8), respectively; unpublished results, calculated based on data from Torres et $a l^{(20)}$ ) or at the end of pregnancy ${ }^{(12)}$, despite differences in PUFA intake pattern. Furthermore, lactating adolescents presented significantly higher levels of EPA, DHA, $n-3: n-6$ ratio and total $n-6, n-3$ and LCPUFA in erythrocytes than lactating adults. Regarding DHA indices, Brazilian pregnant ${ }^{(12)}$ and lactating ${ }^{(20)}$ adults and lactating adolescents presented lower $22: 6 n-3: 22: 5 n-6$ ratio and higher $22: 5 n-6: 22: 4 n-6$ ratio than Dutch pregnant women ${ }^{(24)}$, suggesting a worse DHA status in the Brazilian women. On the other hand, EFASTI was not different between Dutch ${ }^{(24)}$ and Brazilian women. Further comparison of erythrocyte EFA and DHA indices of Brazilian lactating adolescents with adolescent and adult lactating women from different countries was not possible due to lack of data.

In lactating adults, PUFA status improves during the postpartum period, as shown by increases from 2 to $16-32$ weeks postpartum in erythrocyte $18: 2 n-6^{(51,52)}, 20: 4 n-6$, $20: 5 n-3$ and $22: 5 n-3^{(51)}$. Consistently, lactating adolescents presented positive associations of time postpartum with erythrocyte EFASTI and polyunsaturated:saturated fat ratio. In contrast with the increase in several PUFA, erythrocyte DHA decreased in lactating adults during the postpartum period $^{(51,52)}$, but for the present group of lactating adolescents, erythrocyte DHA was not associated with time postpartum.

MMP, which involves contribution of all fatty acids present in the phospholipids, might be affected by shifts in fatty acid composition. High MMP may be indicative of EFA and LCPUFA deficiency, since fatty acids with more unsaturated bonds present lower melting points ${ }^{(28)}$. Pregnancy and lactation induce changes in contents of these fatty acids that result in increased MMP of plasma phospholipids, especially in the former condition ${ }^{(28)}$. Brazilian lactating adolescents presented a lower EM MMP $(P<0.01)$ than Brazilian pregnant adolescents $\left(29.3(\mathrm{SD} 1.5)^{\circ} \mathrm{C}\right.$; unpublished results, calculated based on data from Meneses $\left.{ }^{(53)}\right)$. This difference follows the same trend reported for plasma phospholipid MMP in adult women $^{(28)}$.

Since all fatty acids contribute to MMP, several correlations between individual fatty acids and EM MMP have been found in the present study and in other studies using either milk $\mathrm{MMP}^{(43)}$ or plasma phospholipids $\mathrm{MMP}^{(28)}$. A more comprehensive approach to explain the variability of MMP is through multiple regression analysis, in which erythrocyte individual fatty acids and status indices, and other independent variables, are included in the models. In the present study, the three models (Table 4) obtained by multiple regression analysis for erythrocyte MMP included as independent variables with negative coefficients some individual LCPUFA and total PUFA, in separate models, as well as DHA and $22: 6 n-3: 22: 5 n-6$ ratio, also in separate models. These results suggest the use of erythrocyte MMP as a possible comprehensive biochemical marker of LCPUFA status in lactating adolescents. Time postpartum and years post-menarche presented negative coefficients for MMP variability in separate multiple regression models. A decrease in MMP with the advancing weeks postpartum in the lactating adolescents is consistent with the observed improvement of PUFA status during this period. Similarly, a decrease in MMP with longer time periods between menarche and lactation might be related to a possible better PUFA status in adolescents with longer post-menarche intervals.

In general, breast milk fatty acid composition of the lactating adolescents in the present study was not different from that observed before in Brazilian adults ${ }^{(20)}$ of similar socioeconomical and cultural backgrounds. It could be expected that adolescents would have less PUFA, especially 20:4n-6 and $22: 6 n-3$, in their milk than lactating adults because of two factors. Dietary intake of $n-3$ and $n-6$ PUFA in the present group of adolescents was lower than in lactating adults but their status was similar ${ }^{(20)}$ and the growing tissues of adolescents would compete with the mammary gland for essential nutrients ${ }^{(54)}$, similar to what occurs during pregnancy, when maternal tissues of the adolescents that are still growing compete with fetal tissues for nutrients ${ }^{(55,56)}$. However, in the case of the present group of adolescents there were no significant differences of individual LCPUFA in breast milk between adolescents and adults. It is possible that transfer of EFA and LCPUFA to the mammary gland in adolescents is preferential in relation to maternal tissues and as efficient as in adult women. 
Recently, Brenna et al. ${ }^{(57)}$ reported a descriptive meta-analysis on breast milk DHA and AA concentrations that included sixty-five studies from different countries worldwide. The calculated DHA and AA concentrations; ( $\mathrm{g} / 100 \mathrm{~g}$ fatty acids) were 0.32 (SD 0.22 ) and 0.47 (SD 0.13), respectively, and variability $(\mathrm{CV} \%)$ for DHA was $69 \%$ and for AA was $28 \%$. The higher CV\% for DHA $(50 \%)$ than for AA (38\%) in milk from adolescents belonging to the same population group in the present study is consistent with those findings. It should be noted that AA and especially DHA concentrations in milk from the lactating adolescents of the present study were lower $(P=0.019$ and $P=0.006$, respectively) than the calculated mean concentrations of these fatty acids in the meta-analysis ${ }^{(57)}$.

In a previous study with lactating adult women ${ }^{(20)}, n-6$ and $n$-3 fatty acids in human milk presented several associations, evaluated through Pearson correlation and multiple regression analyses, with NEFA and erythrocyte fatty acid composition. In contrast, fewer associations were found for lactating adolescents. The only two significant models found for breast milk fatty acids determined by multiple regression analysis were those for milk DHA (Table 5), especially the models including DHA indices and MMP as independent variables. Therefore, it seems that the PUFA concentration in milk from adolescents was less directly dependent on their concentrations in plasma NEFA and on maternal status assessed through erythrocyte fatty acid composition than in milk from adult women, except for milk DHA concentration, which was highly associated with DHA status of the lactating adolescents.

Several observational and intervention studies have shown that maternal intake of DHA is the most important factor determining the secretion of DHA in human milk ${ }^{(58)}$. Despite an apparently lower intake of $n$-3 LCPUFA and the superimposed nutritional demands of lactation with adolescence, the group of adolescents in the present study presented EFA and LCPUFA status and concentrations in milk that were similar to those of Brazilian lactating adults ${ }^{(20)}$, suggesting that these lactating adolescents were not disadvantaged regarding PUFA status. Furthermore, milk DHA was associated with erythrocyte indices of maternal LCPUFA and DHA states, providing evidence that breast milk DHA of lactating adolescents is dependent on maternal status, as occurs with adult women.

\section{Acknowledgements}

The authors are grateful for the cooperation of the volunteers participating in this study. The authors declare that there are no conflicts of interest and thank the funding support by the Conselho Nacional de Desenvolvimento Científico e Tecnológico (CNPq), Coordenação de Aperfeiçoamento de Pessoal de Nível Superior (CAPES) and Fundação Carlos Chagas de Amparo à Pesquisa do Estado do Rio de Janeiro (FAPERJ), Brazil. F.M. and N.M.F.T. thank $\mathrm{CNPq}$ for the granting of the $\mathrm{PhD}$ and the Research Fellowships, respectively. N.M.F.T. obtained funding for the study.

\section{References}

1. Population Reference Bureau (2000) Meeting young women's reproductive and sexual health needs. http://www.phishare.org/ files/227_meeting_young_women_repro_needs.pdf
2. Ministério da Saúde - Datasus (2003) Sinasc - Sistema de Informações sobre Nascidos Vivos. Brasil: Datasus/MS/SVS/ DASIS; available at http://tabnet.datasus.gov.br

3. Mascarenhas MR, Zemel BS, Tershakovec AM \& Stallings VA (2001) Adolescence. In Present Knowledge in Nutrition, 8th ed., pp. 426-438 [BA Bowman and RM Russell, editors]. Washington, DC: ILSI Press.

4. Moran VH (2007) A systematic review of dietary assessments of pregnant adolescents in industrialised countries. $\mathrm{Br} J$ Nutr 97, 411-425.

5. Andrade RG, Pereira RA \& Sichieri R (2003) Consumo alimentar de adolescentes com e sem sobrepeso do município do Rio de Janeiro [Food intake in overweight and normal-weight adolescents in the city of Rio de Janeiro]. Cad Saúde Públ 19, 1485-1495.

6. Barros DC, Pereira RA, Gama SGN \& Leal MC (2004) $\mathrm{O}$ consumo alimentar de gestantes adolescentes no município do Rio de Janeiro [Food consumption by pregnant adolescents in Rio de Janeiro Brazil]. Cad Saúde Públ 20, Suppl., S121-S129.

7. Jensen RG (1999) Lipids in human milk. Lipids 34, 1243-1271.

8. Yuhas R, Pramuk K \& Lien EL (2006) Human milk fatty acid composition from nine countries varies most in DHA. Lipids 41, $851-858$.

9. Crawford M (2000) Placental delivery of arachidonic and docosahexaenoic acids: implications for the lipid nutrition of preterm infants. Am J Clin Nutr 71, Suppl. 1, 275S-284S.

10. Parra MS, Schnaas L, Meydani M, Perroni E, Martinez S \& Romieu I (2002) Erythrocyte cell membrane phospholipid levels compared against reported dietary intakes of polyunsaturated fatty acids in pregnant Mexican women. Public Health Nutr 5, 931-937.

11. Innis SM \& Elias SL (2003) Intakes of essential n-6 and n-3 polyunsaturated fatty acids among pregnant Canadian women Am J Clin Nutr 77, 473-478.

12. Pontes PV, Torres AG, Trugo NMF, Fonseca VM \& Sichieri $R$ (2006) $n-6$ and $n-3$ long-chain polyunsaturated fatty acids in the erythrocyte membrane of Brazilian preterm and term neonates and their mothers at delivery. Prostaglandins Leukot Essent Fatty Acids 74, 117-123.

13. Henderson RA, Jensen RG, Lammi-Keefe CJ, Ferris AM \& Dardick KR (1992) Effect of fish oil on the fatty acid composition of human milk and maternal and infant erythrocytes. Lipids 27, 863-869.

14. Jensen CL, Maude M, Anderson RE \& Heird W (2000) Effect of docosahexaenoic acid supplementation of lactating women on the fatty acid composition of breast milk lipids and maternal and infant plasma phospholipids. Am J Clin Nutr 71, Suppl., 292S-299S

15. Makrides M \& Neumann MA (1996) Effect of maternal docosahexaenoic acid (DHA) supplementation on breast milk composition. Eur J Clin Nutr 50, 352-357.

16. Rocquelin G, Tapsoba S, Dop MC, Mbemba F, Traissac P \& Martin-Prével Y (1998) Lipid content and essential fatty acid (EFA) composition of mature Congolese breast milk are influenced by mothers' nutritional status: impact on infants' EFA supply. Eur J Clin Nutr 52, 164-171.

17. Boris J, Jensen B, Salvig JD, Secher NJ \& Olsen SF (2004) A randomized controlled trial of the effect of fish oil supplementation in late pregnancy and early lactation on the $n-3$ fatty acid content in human breast milk. Lipids 39, 1191-1196.

18. Neville MC \& Picciano MF (1997) Regulation of milk lipid secretion and composition. Аnпи Rev Nutr 17, 159-184.

19. Marangoni F, Agostoni C, Lammardo AM, Bonvissuto M, Giovannini M, Galli C \& Riva E (2002) Polyunsaturated fatty acids in maternal plasma and in breast milk. Prostaglandins Leukot Essent Fatty Acids 66, 535-540. 
20. Torres AG, Ney JG, Meneses F \& Trugo NMF (2006) Polyunsaturated fatty acids and conjugated linoleic acid isomers in breast milk are associated with plasma non-esterified and erythrocyte membrane fatty acid composition in lactating women. Br J Nutr 95, 517-524.

21. Ruyle M, Connor WE, Anderson GJ \& Lowensohn RI (1990) Placental transfer of essential fatty acids in humans: venousarterial difference for docosahexaenoic acid in fetal umbilical erythrocytes. Proc Natl Acad Sci U S A 87, 7902-7906.

22. Guesnet P, Pugo-Gunsam P, Maurage C, Pinault M, Giraudeau B, Alessandri JM, Durand G, Antoine JM \& Couet C (1999) Blood lipid concentrations of docosahexaenoic and arachidonic acids at birth determine their relative postnatal changes in term infants fed breast milk or formula. Am J Clin Nutr 70, 292-298.

23. Ghebremeskel K, Min Y, Crawford MA, Nam JH, Kim A, Koo JN \& Suzuki H (2000) Blood fatty acid composition of pregnant and non-pregnant Korean women: red cells may act as a reservoir of arachidonic acid and docosahexaenoic acid for utilization by the developing fetus. Lipids 35, 567-574.

24. Vlaadingerbroek H \& Hornstra G (2004) Essential fatty acids in erythrocyte phospholipids during pregnancy and at delivery in mothers and their neonates: comparison with plasma phospholipids. Prostaglandins Leukot Essent Fatty Acids 71, $363-374$

25. Hunter D (1998) Biochemical indicators of dietary intake. In Nutritional Epidemiology, 2nd ed., pp. 174-243 [W Willett, editor]. New York: Oxford University Press.

26. Torres AG, Meneses F \& Trugo NMF (2000) Fatty acid content of erythrocyte membrane in Brazilian lactating women and its relation with dietary intake. FASEB $J \mathbf{1 4}$, A209 Abstr.

27. Torres AG, Meneses F \& Trugo NMF (2002) Content of conjugated linoleic acids, cis-9,trans-11, 18:2 and trans10,cis-12, 18:2 in breast milk from Brazilian women: association with milk composition and diet. Adv Exp Med Biol 503, 273-274.

28. Holman RT, Johnson SB \& Ogburn PL (1991) Deficiency of essential fatty acids and membrane fluidity during pregnancy and lactation. Proc Natl Acad Sci 88, 4835-4839.

29. Fokkema MR, Smit EN, Martini IA, Woltil HA, Boersma ER \& Muskiet FAJ (2002) Assessment of essential fatty acid and $\omega-3$

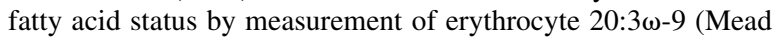

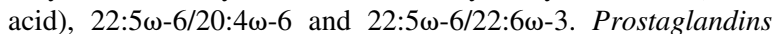
Leukot Essent Fatty Acids 67, 345-356.

30. Hoffman DR \& Uauy R (1992) Essentiality of dietary $\omega 3$ fatty acids for premature infants: plasma and red blood cell fatty acid composition. Lipids 27, 886-895.

31. World Health Organization (1995), The Use and Interpretation of Anthropometry, Technical Report Series no. 854. Geneva: World Health Organization.

32. Núcleo de Estudos e Pesquisas em Alimentos/Universidade Estadual de Campinas (2004) Tabela Brasileira de Composição de Alimentos - TACO [Brazilian Food Composition Table TACO]. Campinas: UNICAMP/ Ministério da Saúde.

33. Lucas A, Gibbs JAH, Lyster RLJ \& Baum JD (1978) Crematocrit: simple clinical technique for estimating fat concentration and energy value of human milk. British Med J 1, $1018-1020$.

34. Trugo NMF, Donangelo CM, Koury JC, Silva MI \& Freitas LA (1988) Concentration and distribution pattern of selected micronutrients in preterm and term milk from urban Brazilian mothers during early lactation. Eur J Clin Nutr 42, 497-507.

35. Perry NA \& Doan FJ (1950) A picric acid method for the simultaneous determination of lactose and sucrose in dairy products. J Dairy Sci 33, 176-185.

36. Broekhuyse RM (1974) Long-term storage of erythrocytes for quantitative analyses of lipids. Clin Chim Acta 52, 53-58.
37. Bligh EG \& Dyer WJ (1959) A rapid method of total lipid extraction and purification. Can J Biochem Physiol 37, 911-917.

38. Jensen RG, Lammi-Keefe C \& Koletzko B (1997) Representative sampling of human milk and the extraction of fat for analysis of environmental lipophilic contaminants. Toxicol Environ Chem 62, 229-247.

39. Kramer JKG, Fellner V, Dugan MER, Sauer FD, Mossoba MM \& Yurawecz MP (1997) Evaluating acid and base catalysts in the methylation of milk and rumen fatty acids with special emphasis on conjugated dienes and total trans fatty acids. Lipids 32, 1219-1228.

40. Torres AG, Trugo NMF \& Trugo LC (2002) Mathematical method for the prediction of retention times of fatty acid methyl esters in temperature-programmed capillary gas-chromatography. J Agric Food Chem 50, 4156-4163.

41. Polette A, Durand P, Floccard B \& Blache D (1992) A method for specific analysis of free fatty acids in biological samples by capillary gas chromatography. Anal Biochem 206, 241-245.

42. Ney JG, Torres AG \& Trugo NMF (2004) Análise de ácidos graxos não-esterificados de plasma humano por cromatografia gasosa capilar com injeção sem divisão de fluxo [Analysis of nonesterified fatty acids in human plasma by capillary gas chromatography with splitless injection]. Quím Nova 27, 561-566, available at http://www.scielo.br/pdf/qn/v27n4/20796.pdf

43. Glew RH, Huang Y-S, VanderJagt TA, Chuang L-T, Bhatt SK, Magnussen MA \& VanderJagt DJ (2001) Fatty acid composition of the milk lipids of Nepalese women: correlation between fatty acid composition of serum phospholipids and melting point. Prostaglandins Leukot Essent Fatty Acids 65, 147-156.

44. Institute of Medicine (2002) Dietary Reference Intakes for Energy, Carbohydrate, Fiber, Fat, Fatty Acids, Cholesterol, Protein, and Amino Acids. Washington, DC: The National Academies Press.

45. Allen LH (2001) Pregnancy and lactation. In Present Knowledge in Nutrition, 8th ed., pp. 403-415 [BA Bowman and RM Russell, editors]. Washington, DC: ILSI Press.

46. Butte NF, Hopkinson JM, Mehta N, Moon JK \& Smith EO (1999) Adjustments in energy expenditure and substrate utilization during late pregnancy and lactation. Am J Clin Nutr 69, 299-307.

47. Torres AG, Ney JG, Ribeiro M \& Trugo NMF (2004) Plasma nonesterified fatty acid composition is different in lactating and nonpregnant nonlactating women. Adv Exp Med Biol 554, 511-514.

48. Tigas S, Sunehag A \& Haymond MW (2002) Metabolic adaptation to feeding and fasting during lactation in humans. J Clin Endocrinol Metab 87, 302-307.

49. Heptulla R, Smitten A, Teague B, Tamborlane WV, Ma Y-Z \& Caprio S (2001) Temporal patterns of circulating leptin levels in lean and obese adolescents: relationships to insulin, growth hormone, and free fatty acids rhythmicity. J Clin Endocrinol Metab 86, 90-96.

50. Koletzko B, Cetin I, Brenna T, et al. (2007) Dietary fat intakes for pregnant and lactating women. Br J Nutr 98, 873-877.

51. Otto SJ, van Houwelingen AC, Badart-Smook A \& Hornstra G (2001) Comparison of the peripartum and postpartum phospholipids polyunsaturated fatty acid profiles of lactating and nonlactating women. Am J Clin Nutr 73, 1074-1079.

52. Torres AG, Meneses F \& Trugo NMF (2002) Erythrocyte membrane fatty acid composition of Brazilian nursing women: effect of the lactational period. Adv Exp Med Biol 503, 321-322.

53. Meneses $F$ (2005) Influência da gestação e lactação sobre o metabolismo e estado de ácidos graxos em adolescentes e sua relação com a composição do leite [Influence of pregnancy and lactation on fatty acid status and metabolism in adolescents and their relation with milk composition]. DSc. 
Thesis, Universidade Federal do Rio de Janeiro; available at http://teses.ufrj.br/IQ_d/FlaviaMenesesPereiraPresta.PDF

54. Motil KJ, Kertz B, Montandon CN \& Ellis KJ (1996) Dietary nutrients are diverted from milk production to body stores in lactating adolescents. FASEB $J \mathbf{1 0}, 1095$.

55. Hediger ML, Scholl TO \& Schall JI (1997) Implications of the Camden Study of adolescent pregnancy: interactions among maternal growth, nutritional status, and body composition. Ann N Y Acad Sci 817, 281-291.
56. Scholl TO, Hediger ML \& Schall JI (1997) Maternal growth and fetal growth: pregnancy course and outcome in the Camden Study. Ann N Y Acad Sci 817, 292-301.

57. Brenna JT, Varamini B, Jensen RG, Diersen-Schade DA, Boettcher JA \& Arterburn LN (2007) Docosahexaenoic and arachidonic acid concentrations in human breast milk worldwide. Am J Clin Nutr 85, 1457-1464.

58. Innis SM (2007) Human milk: maternal dietary lipids and infant development. Proc Nutr Soc 66, 397-404. 